\title{
O perfil do idoso e análise das principais demandas em busca do apoio psicológico por idosos no Serviço Escola de Psicologia (SEPSI) da Universidade de Gurupi
}

\section{Oldder profile and analysis of major demands in search of psychological support by elders in the Serviço Escola de Psicologia (SEPSI) of the University of Gurupi}

Monara Pereira de Sousa1, Nathália Japiassú de Paiva Carvalho², Larissa Queiroz Azevedo de Aquino ${ }^{3}$.

O presente estudo propôs verificar as principais queixas relatadas por idosos ao buscar apoio psicológico no Serviço Escola de Psicologia da Universidade de Gurupi, entre os anos de 2015 a 2018. Trata-se de uma pesquisa documental, exploratória descritiva, com abordagem qualitativa e quantitativa. Foram incluídas as triagens realizadas no período de janeiro de 2015 a junho de 2018; triagens de idosos com idade mínima de 60 anos; que tenha assinado o Termo de Consentimento Livre Esclarecido (TCLE) designado pelo SEPSI. Os dados foram tabulados e analisados por meio de ferramentas da estatística descritiva e a abordagem qualitativa realizada por meio da análise de conteúdo. Houve predomínio de idosos do sexo feminino, casados, com idade entre 60 e acima de 81 anos, grande parte com escolaridade de ensino fundamental incompleto, aposentados. Os mesmos procuraram 0 Serviço voluntariamente e suas principais queixas relatadas indicam tristeza, choro frequente, solidão, entre outras, e após a triagem foram encaminhados para a psicoterapia. A realização desta pesquisa contribuiu para a identificação das principais demandas trazidas por idosos, além de proporcionar um esclarecimento acerca da realidade vivenciada pelos mesmos.

Palavras-chave: Idosos. Qualidade de vida. Saúde mental na terceira idade.

\section{ABSTRACT}

This study aimed to verify the main complaints reported by the elderly when seeking psychological support at the Serviço Escola de Psicologia of the University of Gurupi, between 2015 and 2018. It is a descriptive exploratory documentary research with a qualitative and quantitative approach. Screening performed from January 2015 to June 2018 was included; screening of elderly with a minimum age of 60 years; who has signed the Informed Consent Form (ICF) designated by SEPSI. Data were tabulated and analyzed using descriptive statistics tools and the qualitative approach performed through content analysis. There was a predominance of married elderly women, aged 60 and over 81 years old, most of them with incomplete elementary school education, retirees. They sought the Service voluntarily and their main reported complaints indicate sadness, frequent crying, loneliness, among others, and after screening were referred to psychotherapy. The accomplishment of this research contributed to the identification of the main demands brought by the elderly, besides providing a clarification about the reality lived by them.

Keywords: Elderly. Quality of life. Mental health in the elderly.
${ }^{1}$ Psicóloga pela Universidade de Gurupi/UnirG.

E-mail: monara-cy@hotmail.com

${ }^{2}$ Psicóloga pela Universidade de Gurupi/UnirG.

E-mail:

nathaliajapiassu@gmail.com

${ }^{3}$ Mestre, Docente da Universidade de Gurupi/UnirG

E-mail: larissa@unirg.edu.br 


\section{INTRODUÇÁOO}

O aumento de idosos é explicito na população mundial. De acordo com a Pesquisa Nacional por Amostra de Domicílios (PNAD), divulgado pelo Instituto Brasileiro de Geografia e Estatística (IBGE) ${ }^{1}$, dados apontam que houve um aumento na população idosa de 4,8 milhões, de 2012 a 2017. Em 2012, o grupo etário a partir de 60 anos representava 25,4 milhões e em 2017 estimavam-se 30,2 milhões. Dentre este número, as mulheres correspondem a $56 \%$, ou seja, 16,9 milhões de idosos e os homens $44 \%$, correspondendo a 13,3 milhões de idosos.

O envelhecimento pode ser caracterizado de duas maneiras: primário, um processo biológico natural e secundário, associado a modificações do ambiente que ocasionam o envelhecimento. ${ }^{2}$ Associada ao envelhecimento está a qualidade de vida, que não está relacionada unicamente a fatores biológicos, mas também está interligada a condições que colaboram para o convívio social e autonomia, estas são: psicológica, social, econômica e cultural. $^{3}$

O aumento de idade da população provoca alterações no aspecto das doenças. ${ }^{4}$ Neste sentido, a morbidade em idosos está associada ao processo da longevidade, acompanhada por doenças silenciosas crônicas. ${ }^{5}$ Essas doenças podem acarretar uma perturbação funcional, bem como ansiedade, depressão e privação de sono, associados a dores crônicas. ${ }^{6}$

Além disso, os transtornos de ansiedade e depressão são os que acometem os idosos com mais frequência, relacionado à compreensão de deficiência de auxílio social, bem como, inutilidade, intensificação de doenças crônicas, e perdas de papéis sociais, fatores que geram sofrimento psicológico e físico. ${ }^{7}$

Em relação à depressão há profissionais da saúde que não priorizam os sintomas no envelhecimento, já que consideram como aspecto natural da velhice, e comorbidade em relação à sintomas físicos de outras doenças, fato que causa a infrequência de diagnósticos de depressão em idosos. ${ }^{8}$ Além disso, entre esta população, o predomínio da depressão varia entre 4,7 a $36,8 \%$ no Brasil.

Nesse contexto percebe-se que o papel do psicólogo é de extrema relevância, já que estes transtornos por vezes são subtratados, difíceis de obter resultados específicos. Em consequência da vulnerabilidade dos idosos, a psicologia pode trazer contribuições para enfrentar o sofrimento presente na terceira idade. A psicoterapia pode contribuir com a qualidade de vida do idoso, e requer uma compreensão do profissional acerca dos 
processos de envelhecimento. A psicoterapia psicodinâmica breve é uma das ferramentas de intervenção, pois auxilia o idoso em sua adaptação ao envelhecimento, bem como, ressignificações, perdas, crises, dentre outros. ${ }^{9}$

Uma pesquisa realizada no Vale do Rio Pardo, no Rio Grande do Sul, apontou que idosos a partir de 60 anos procuraram tratamento psicoterapêutico, apresentando motivos de tristezas e pessimismo, dentre esses a maioria eram mulheres. ${ }^{10}$

Existe grande dificuldade em encontrar suportes bibliográficos e conteúdos sobre as principais demandas psicológicas apresentadas por idosos. Deste modo indaga-se sobre as principais demandas trazidas por idosos em busca de apoio psicológico.

Portanto, esta pesquisa objetivou verificar as principais queixas relatadas por idosos ao buscar apoio psicológico no Serviço Escola de Psicologia (SEPSI) da Universidade UnirG, entre os anos de 2015 a 2018; assim como, delinear o perfil sociodemográfico dos idosos; apresentar o índice de atendimentos realizados com idosos nos últimos 03 (três) anos; verificar os principais encaminhamentos realizados após a triagem realizada no SEPSI; mensurar a procura pelo apoio psicológico por encaminhamento e voluntário; e compreender os principais fatores que podem desencadear o adoecimento psíquico do idoso.

\section{MATERIAIS E METODOS}

A pesquisa foi realizada no Serviço Escola de Psicologia (SEPSI) da Universidade UnirG em Gurupi-TO, entre os meses de setembro a outubro de 2018, onde realizou-se o levantamento de prontuários de pacientes idosos (acima de 60 anos) a fim de verificar as principais queixas relatadas por estes ao buscar apoio psicológico, no período entre os anos de 2015 a 2018. Trata-se de uma pesquisa documental, exploratória descritiva, com abordagem quanti e qualitativa.

Conforme informações cedidas pela coordenação do SEPSI, de janeiro de 2015 a junho de 2018 ocorreram 808 atendimentos, dentre estes, infantis, adolescentes, adultos e idosos. Contudo, selecionou-se apenas os casos de idosos, considerados $100 \%$ da amostra, a partir dos critérios de inclusão e exclusão.

Foram incluídas fichas de triagens realizadas no período de janeiro de 2015 a junho de 2018 (por se tratar de um período com alto índice de atendimentos); triagens de adultos com idade mínima de 60 anos; triagens de clientes que tenham assinado o Termo de Consentimento Livre Esclarecido (TCLE) designado pelo SEPSI antes do atendimento. 
Foram excluídas as triagens em que não tenham assinado o TCLE, que apresentem queixas relatadas por terceiros e/ou responsáveis pelos idosos.

Os possíveis riscos que a pesquisa ofereceu à saúde física e mental foram mínimos, pois referiam-se à análise documental que garante a privacidade dos participantes, as informações pessoais cedidas permaneceram confidenciais, nomes fictícios (quando necessário) para a divulgação dos dados coletados. A pesquisa não causou nenhum tipo de incômodo, pois não houve contato direto com os participantes, nem exposição dos dados de identificação dos mesmos.

Os benefícios se basearam em melhores informações a respeito da saúde mental na terceira idade. Buscou-se obtenção de maiores dados e conteúdos sobre a temática, e assim através da publicação dos resultados deste levantamento (em congressos e artigo científico), propiciar compreensão acerca do adoecimento, para facilitar o processo de prevenção e intervenção aos idosos. Por fim, estas informações são relevantes para proporcionar aperfeiçoamentos dos assuntos sobre a terceira idade.

Primeiramente, solicitou-se a autorização do SEPSI, local onde foi realizada a pesquisa. Em seguida, o projeto foi submetido para aprovação junto ao Comitê de Ética em Pesquisa, conforme a resolução CNS №. 466/2012, por se tratar de pesquisa envolvendo seres humanos, sendo aprovado com o parecer de número 2.849.424, em seguida se iniciou a coleta de dados.

Os TCLEs, já estavam assinados pelos pacientes que buscaram o SEPSI no período designado, por se tratar de parte dos procedimentos rotineiros adotados pelo SEPSI, desta forma, autorizado o acesso aos dados dos atendimentos registrados em prontuários, e como parte destes a Ficha de Triagem, o documento acessado nesta pesquisa. Foram selecionadas as triagens que se enquadraram nos critérios de inclusão e exclusão, e analisadas na íntegra para melhor compreensão dos dados.

O material foi utilizado especificamente para os propósitos desejados da pesquisa e após as tabulações e análises trouxeram uma maior compreensão do tema proposto, que possibilitou medidas de proteção à confidencialidade das informações obtidas.

Utilizou-se a ficha de triagem dos atendimentos do SEPSI como instrumento de coleta de dados, bem como a análise estatística descritiva, baseada em porcentagens, com o auxílio do programa Microsoft Excel versão 2013.

A busca documental se deu entre os meses de setembro e outubro de 2018 , em dias e horários previamente agendados com o local. 


\section{RESULTADOS}

O SEPSI tem por objetivo primordial o desenvolvimento de atividades concernentes aos diversos campos da Psicologia que se destinam a formação profissional dos alunos do curso de Psicologia da Universidade de Gurupi e ao atendimento da comunidade. Os estágios são supervisionados por psicólogos vinculados ao departamento de psicologia da universidade e inscritos no CRP /TO.

Os estágios supervisionados incluem dois tipos de atividades realizadas durante a semana, sendo: Atividades de Campo - No estágio básico, incluem atividades de planejamento, observação, relatórios, pesquisas, palestras e apresentação de seminários e atuação do estagiário, incluindo atendimentos clínicos. Supervisão - destinada ao contato direto do grupo de alunos com o professor supervisor, para acompanhamento das atividades de campo.

Foram analisadas 32 fichas de triagens de janeiro de 2015 a junho de 2018, no qual em 2015 foram realizadas 4 triagens, já no ano de 2016 houve um aumento do número de triagens, que totalizaram em 12, em 2017 o número subiu para 13 e por fim em 2018 três triagens. De acordo com os critérios de inclusão e exclusão 19 fichas foram analisadas, e 13 excluídas devido à ausência de assinaturas nos termos de consentimento, sendo que os mesmos apenas realizaram o procedimento da triagem e não deram seguimento aos atendimentos, por motivos desconhecidos.

Dos 19 idosos que buscaram atendimentos no SEPSI, 17 eram mulheres e apenas 2 eram do sexo masculino, todos residentes na cidade de Gurupi-TO sendo esta a localidade de origem do SEPSI. Os mesmos apresentaram idades variadas, que seguem apresentadas na Figura 1. 


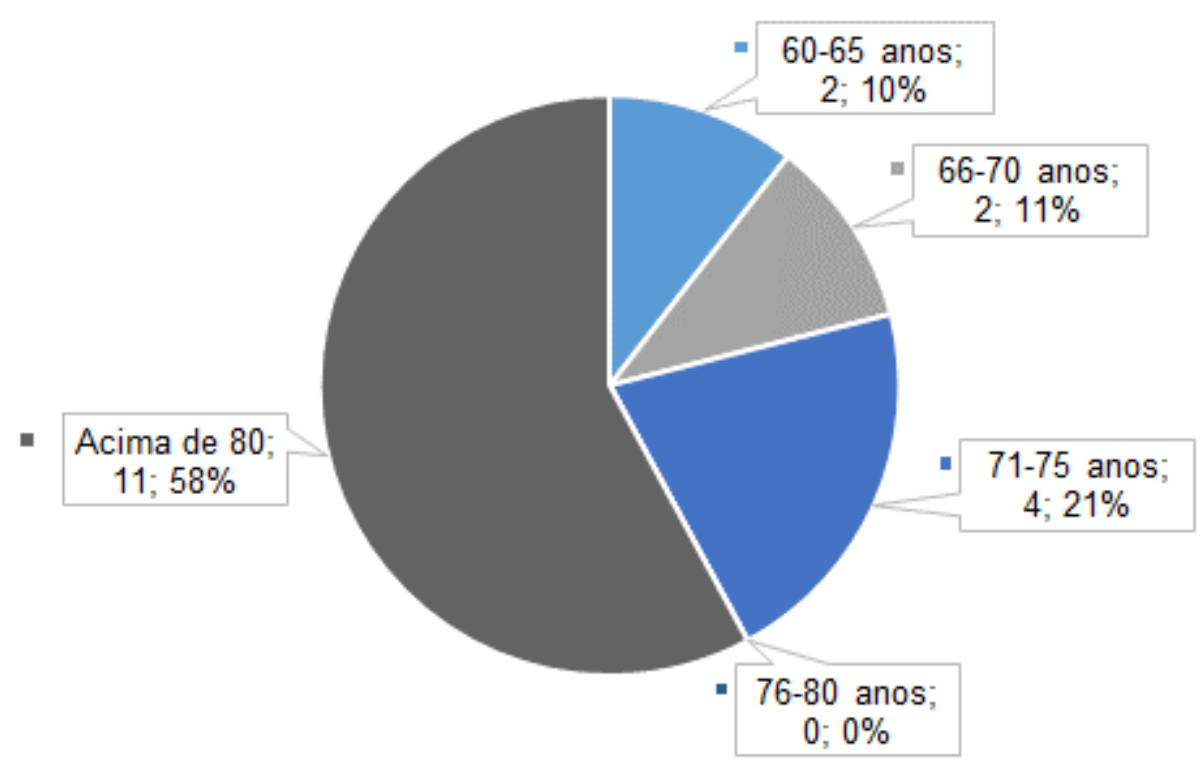

Figura 1. Classe de idade de idosos atendidos no Serviço Escola de Psicologia (SEPSI) da Universidade UnirG em Gurupi-TO entre os anos de 2015 a 2018.

Das 19 triagens analisadas, na faixa etária dos 60 a 65 anos de idade, observou-se um total de 11 idosos, já entre os 66 a 70 anos totalizaram-se 04, de 71 a 75 anos 02 e acima de 81 anos apenas 02 idosos. Portanto, percebe-se que grande parte tem idade de 60 a 65 anos.

Apesar de todos estarem residindo na cidade de Gurupi-TO, suas naturalidades foram distintas, conforme Tabela 1:

Tabela 1. Estado de origem de idosos atendidos no Serviço Escola de Psicologia (SEPSI) da Universidade UnirG em Gurupi-TO entre os anos de 2015 a 2018.

\begin{tabular}{cc}
\hline ESTADO & № DE IDOSOS \\
\hline GOIÁS & 6 \\
TOCANTINS & 4 \\
MINAS GERAIS & 3 \\
MARANHÃO & 2 \\
RIO GRANDE DO SUL & 1 \\
SÃO PAULO & 1 \\
CEARÁ & 1 \\
NÃO INFORMADO & 1 \\
\hline
\end{tabular}

Grande parte dos idosos são do estado de Goiás, o que pode-se sugestionar que deva-se ao fato de o município de Gurupi pertencer ao estado de Goiás até o ano de 1988, 
como também por serem estados vizinhos, com boas relações comerciais e também com grande trânsito entre seus habitantes.

As profissões exercidas pelos idosos também foram variadas e apresentadas na Tabela 2.

Tabela 2. Atividade profissional de idosos atendidos no Serviço Escola de Psicologia (SEPSI) da Universidade UnirG em Gurupi-TO entre os anos de 2015 a 2018.

\begin{tabular}{cc}
\hline PROFISSÃO & № DE IDOSOS \\
\hline APOSENTADO(A) & 9 \\
DO LAR & 3 \\
COSTUREIRA & 2 \\
VENDEDOR (A) & 2 \\
PEDREIRO & 1 \\
PEDAGOGA & 1 \\
NÃO INFORMADO & 1 \\
\hline
\end{tabular}

Dos 19 idosos a maioria é aposentada, com uma totalidade de nove idosos, já três deles são do lar e os demais se dividem entre costureira, vendedora, pedreiro e pedagoga, obtendo apenas um idoso que não teve sua profissão informada.

A aposentadoria é um direito de todos os cidadãos, garantido pela le $i^{11} n^{\circ} 8.213$ de 24 de julho de 1991, tem a finalidade de garantir recursos para auxiliar no processo de idade avançada, tempo de serviço, incapacidade e por outras circunstancias.

Nota-se que, atualmente, mesmo após o alcance da idade estabelecida para aposentadoria, muitos idosos ainda permanecem ativamente trabalhando por razões variadas, sejam por necessidade, para manter o padrão de vida, bem como para que mantenham-se socialmente participativos, entre outros.

Em relação à escolaridade (Figura 2), dos 19 idosos, 8 tem a escolaridade de ensino fundamental incompleto, seguidos de 6 idosos com ensino médio completo, 2 não informaram, 1 possui ensino fundamental completo, $1 \mathrm{com}$ ensino médio incompleto e apenas 1 com ensino superior completo.

A baixa escolaridade ainda é percebida como fator cultural de gerações anteriores, cujos motivos associados podem estar associados a poucas condições financeiras e, por conseguinte, a imposição de um trabalho prematuro. ${ }^{12}$ 
DOI: 10.18606/2318-1419/amazonia.sci.health.v7n3p93-110 Revista Amazônia: Science \& Health 2019, Vol. 7, № 3.
Sousa MP. Carvalho NJP. Aquino LQA.

O perfil do idoso e análise das principais demandas em busca do apoio psicológico por idosos no Serviço Escola de Psicologia (SEPSI) da Universidade de Gurupi



Figura 2. Escolaridade de idosos atendidos no Serviço Escola de Psicologia (SEPSI) da Universidade UnirG em Gurupi-TO entre os anos de 2015 a 2018.

Já em relação ao estado civil (Figura 3), destaca-se que a maioria é casada e apenas uma amasiada, mas percebe-se que há uma quantidade maior de idosos que não possui um companheiro, estes são viúvos, divorciados e solteiro.

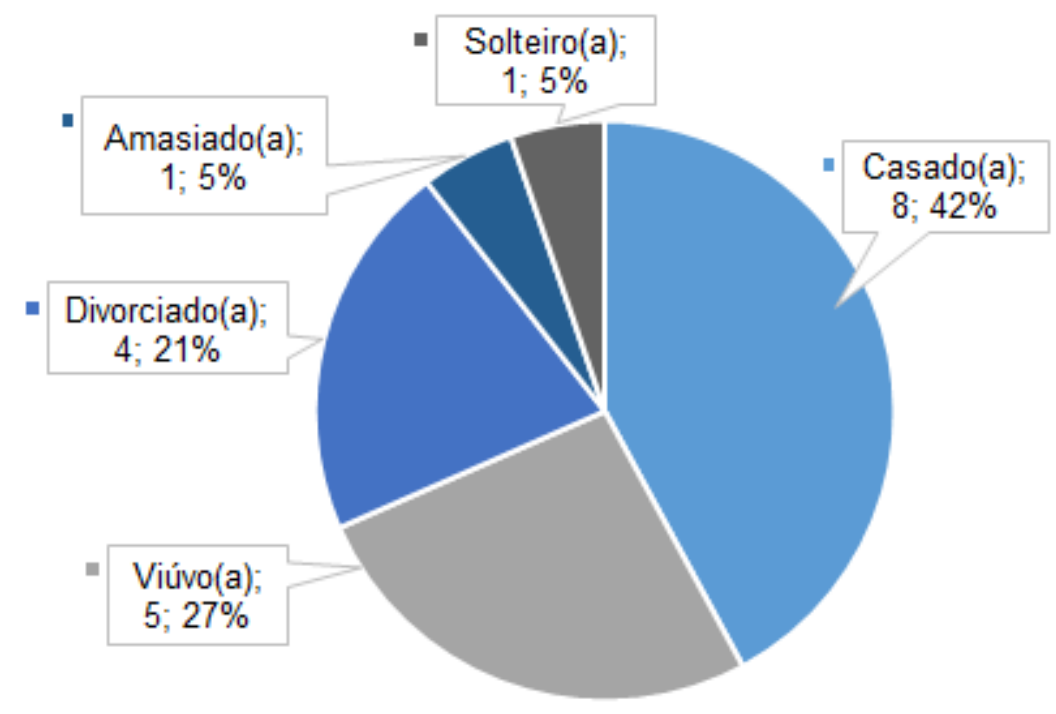

Figura 3. Estado civil de idosos atendidos no Serviço Escola de Psicologia (SEPSI) da Universidade UnirG em Gurupi-TO entre os anos de 2015 a 2018.

A Figura 3 indica que 10 idosos não possui um companheiro e a falta deste pode ser um fator de vulnerabilidade, pois um dos fatores que contribuem para o adoecimento na terceira idade em especial para a depressão é a ausência de um companheiro. ${ }^{13}$ Além 
disso, percebe-se de acordo com as queixas relatadas de não ter a presença de um companheiro também podem ocasionar um sentimento de solidão, podendo o idoso sofrer uma solidão emocional ocasionada pela perda do cônjuge ${ }^{14} \mathrm{e}$ também a solidão social que é caracterizada pela ausência de amigos.

Apesar do grande número de idosos que não possuem companheiros afetivos, todos os idosos possuem filhos, conforme demonstrado na Figura 4.



Figura 4. Número de filhos de idosos atendidos no Serviço Escola de Psicologia (SEPSI) da Universidade UnirG em Gurupi-TO entre os anos de 2015 a 2018.

Percebe-se que 6 idosos possuem dois filhos, 5 possuem três filhos, já 3 idosos têm seis ou mais filhos, 2 possuem apenas um filho, 2 idosos têm cinco filhos e 1 possui quatro filhos (Figura 4).

Todos os idosos atendidos possuem uma religião, dentre eles destacam-se que, 10 são católicos, 7 evangélicos, 1 testemunha de jeová e 1 considera-se cristão (Figura 5). Diante disso, é importante ressaltar que a religião é um consolo diante da solidão e dificuldades frente ao envelhecimento, se tornando então um apoio para os mesmos. ${ }^{15}$

Dos 19 idosos, onze procuraram o Serviço Escola de Psicologia voluntariamente, e os demais foram encaminhados de locais como UBS, Ambulatório da UnirG, Médicos e Escritório Modelo. Ressalta-se que grande parte dos idosos não se apresentou acompanhado para o processo de triagem, sendo que apenas cinco tiveram companhias de filhos, genros, maridos e/ou netos. 
DOI: 10.18606/2318-1419/amazonia.sci.health.v7n3p93-110 Revista Amazônia: Science \& Health 2019, Vol. 7, № 3 .
Sousa MP. Carvalho NJP. Aquino LQA.

O perfil do idoso e análise das principais demandas em busca do apoio psicológico por idosos no Serviço Escola de Psicologia (SEPSI) da Universidade de Gurupi

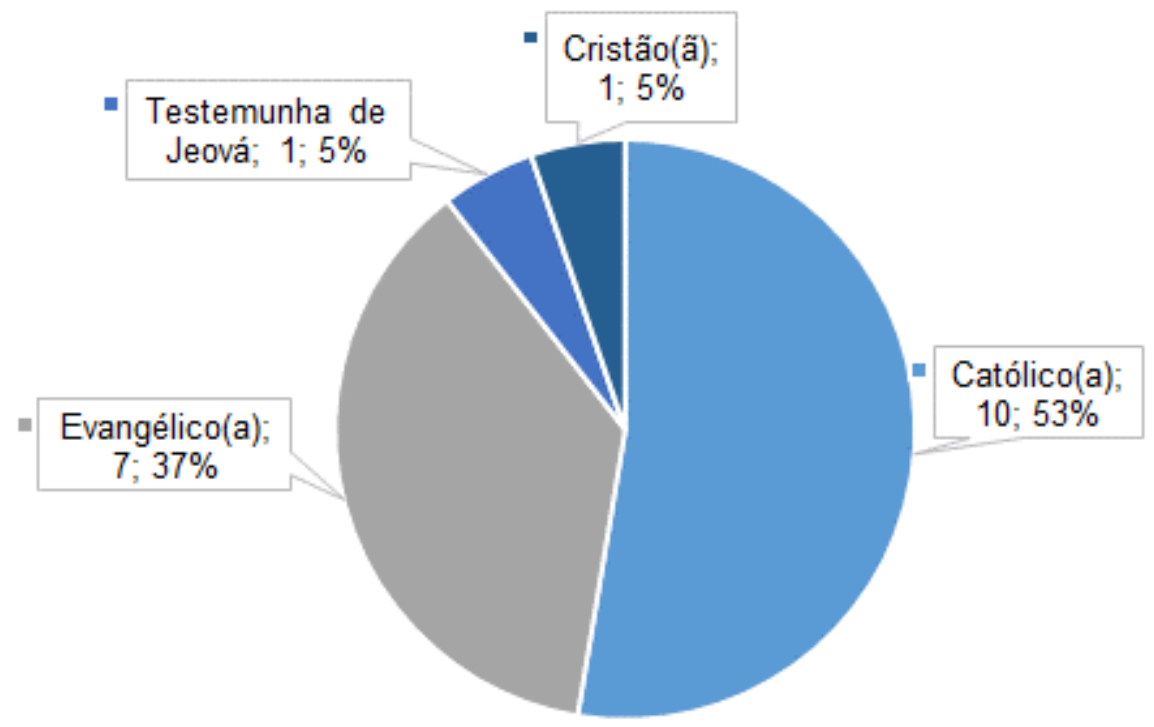

Figura 5. Religião adotada por idosos atendidos no Serviço Escola de Psicologia (SEPSI) da Universidade UnirG em Gurupi-TO entre os anos de 2015 a 2018.

Desta forma, observou-se que a maioria dos idosos realiza tratamento de saúde e ressalta-se que apenas dois não fazem nenhum tratamento de saúde (Figura 6). Dentre os tratamentos de saúde dos idosos, grande parte realiza por apresentar problemas

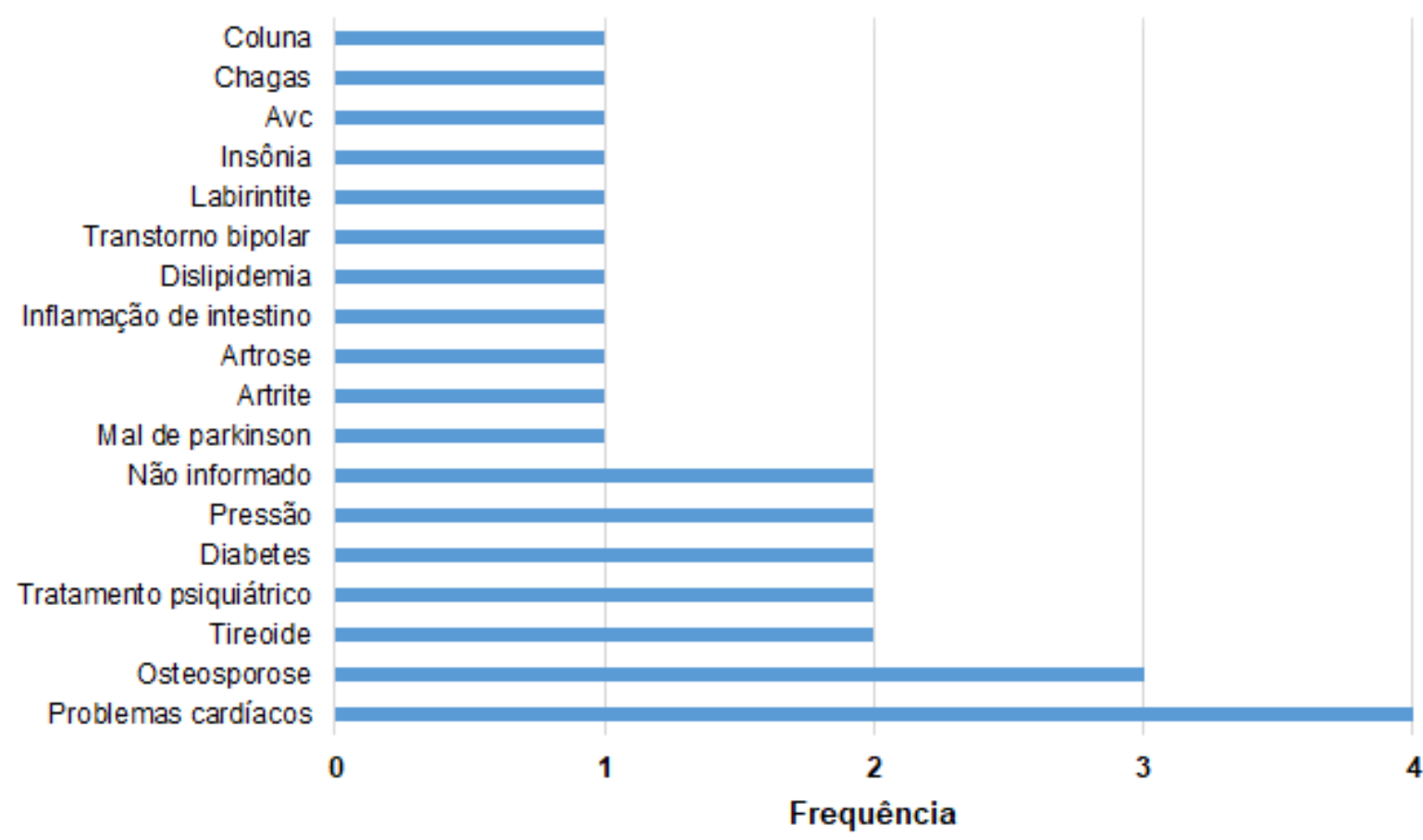

Figura 6. Outro tratamentos de saúde informados por idosos atendidos no Serviço Escola de Psicologia (SEPSI) da Universidade UnirG em Gurupi-TO entre os anos de 2015 a 2018. 
Dentre os medicamentos utilizados, destacam-se com mais frequência o rivotril, fluoxetina, depakene e diazepan.

Ressalta-se que, analisando as demandas trazidas pelos idosos, em alguns casos foram relatadas mais de uma queixa, e estão apresentadas na Figura 7.

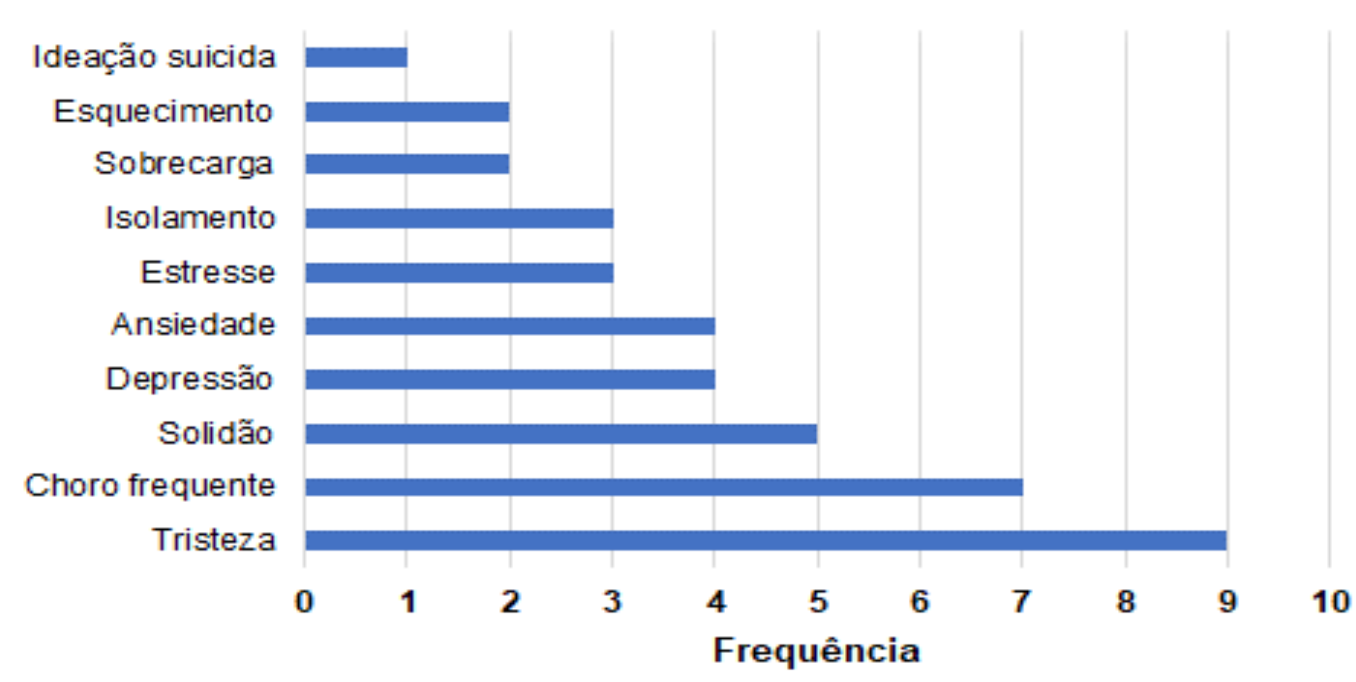

Figura 7. Principais queixas relatadas por idosos atendidos no Serviço Escola de Psicologia (SEPSI) da Universidade UnirG em Gurupi-TO entre os anos de 2015 a 2018.

As principais queixas relatadas por idosos ao buscarem o Serviço Escola de Psicologia da Universidade de Gurupi, foram: tristeza, com maior frequência e representam uma totalidade de 9 idosos. É importante ressaltar que além da tristeza, as outras duas principais queixas como choro frequente relatadas por 7 idosos e solidão informada por 5 , estão relacionadas com a depressão, e esta se deu por uma quantidade de 4 idosos. Ademais, as outras queixas relatadas, foram ansiedade que também representaram 4 idosos, o estresse e isolamento equivalem a 3 idosos, já a sobrecarga e o esquecimento foram relatadas por 2 idosos e por fim, apenas 01 idoso relatou queixa de ideação suicida.

Os relatos abaixo descritos descrevem as queixas supracitadas:

O idoso 1 relatou que no decorrer do tempo vai precisando de tudo. Procurou atendimento, pois gostaria de aprender a lidar com o outro, afirma que estava sobrecarregada com sua rotina familiar, e a dependência dos mesmos. "É tudo é pra cima de mim". Assim como o idoso 2, que relatou problemas com o filho e com a mãe que estava doente.

O idoso 3, relatou que o esposo havia falecido há 04 meses, desde então tinha sentido muita falta, pois viveram 63 anos juntos, não sentindo mais vontade de sair de casa e a 
única atividade que gostava de fazer era cuidar das plantas. A paciente relatou que o processo de inventário dos bens estaria causando preocupação. Queixou-se também de sentir tristeza e solidão.

O idoso 4, queixou-se de solidão devido à ausência dos filhos, já fazia acompanhamento psicológico, mas compareceu somente em três sessões. Já operou de um rim, para retirada de um câncer, permaneceu na cadeira de rodas por um tempo e teve várias complicações de saúde. Relatou que quando os filhos eram menores, pensou em se matar e matar os filhos, porque não via sentido na vida.

O idoso 5 relatou que o médico realizou encaminhamento pois apresenta episódios depressivos leves. Ela queixava-se de tristeza e choro frequente, dizia sentir-se sozinha, afirmava que a tristeza começou após vários lutos subsequentes.

O idoso 6 relatou ter depressão, fraqueza física, passou uma semana em coma, se sentia muito triste, foi medicada por conta da depressão, mas não se adaptou, estava morando sozinha e em processo de separação conjugal e queixava de solidão. Assim como o idoso 7, que queixava-se de tristeza e sem paciência, ficando isolada as vezes e chorava com frequência, dizia que conversar com alguém as vezes melhorava, mas que em alguns dias não queria falar com ninguém.

$\mathrm{O}$ idoso 8 relatou que bateu o carro duas vezes. Tem pensamentos homicidas e suicidas. Sentia medo de tudo. Relatou que quando fazia sexo pensava em coisas bizarras, como sexo entre animais, e pensava no pênis de outros homens. Diz que pensa em outros homens, pensa em matar os netos. Troca objetos de lugar por achar que estão desalinhados e causarão alguma desgraça. Isso ocorre também quando vai escolher uma roupa, tem alucinações visuais de quando era criança e que acha bom. Escuta barulho "raspando" na cabeça.

O idoso 9 fazia uso de psicofármacos, antidepressivos e sofreu 2 infartos. Tudo isso começou com a perda do marido cadeirante e a morte do pai. Ela foi diagnosticada com depressão e síndrome do pânico. O médico indicou que procurasse por tratamento psicoterapêutico.

O idoso 10, afirmava que ocorrem momentos que sente preocupação e afeta 0 emocional, tem medo de sair de casa, tremores, esquecimento, dor de cabeça, chorava as vezes, sentia a sensação que a cabeça ficava grande, não dormia bem. A paciente relatou que as vezes tinha esquecimento de curto e longo prazo, depois voltava a reconhecer pessoas conhecidas. 
O idoso 11 relatou que a aparência era um incômodo. As manchas no rosto a incomodava. $\mathrm{O}$ estresse faz com que as manchas ficassem em evidência. As manchas no rosto tinha feito com que deixasse de sair de casa, pois as pessoas perguntam sobre elas. Relatou ainda estar dormindo muito.

O idoso 12 relatou que separou do esposo há 1 ano e 4 meses, de um casamento de 37 anos. Desde esse período começou a sentir muita tristeza, desânimo e choro fácil. Os filhos a levaram para fazer uma consulta com a psiquiatra, onde foi medicada, a medica lhe orientou a procurar tratamento psicológico.

O idoso 13 procurou atendimento porque o médico encaminhou devido a mesma não ter controle dos esfíncteres, se queixa que vai ao banheiro várias vezes ao dia. $O$ médico afirmou que não tinha nada, exceto nervosismo e ansiedade. Paciente relatou que não dormia direito.

O idoso 14 queixava-se de ter a cabeça confusa, tinha 59 anos de casamento, e era muito esquecido "desde pequeno". Relatou que cuidava da esposa que sofreu um AVC e mal de Parkinson.

O idoso 15 queixava-se de depressão, choro frequente, tristeza e solidão.

O idoso 16 sentia muita tristeza e que lembranças do passado Ihe incomodava, como um abuso sexual e separação dos pais. Relatou vontade de chorar frequentemente mas, para que as filhas não perguntassem, evitava o choro.

O idoso 17 queixou-se de dificuldades para dormir, desânimo, tristeza e choro frequente, devido a não aceitação do casamento do filho.

O idoso 18 tomava medicamento, mas não via melhoras e por isso relatou que "vive no psicólogo", porque não aguenta ir em médicos.

O idoso 19 relatou que queria sair do CAPS, sentia-se discriminada e tinha problemas com a filha. 
DOI: 10.18606/2318-1419/amazonia.sci.health.v7n3p93-110 Revista Amazônia: Science \& Health

2019, Vol. 7, № 3 .

ISSN: 2318-1419
Sousa MP. Carvalho NJP. Aquino LQA.

O perfil do idoso e análise das principais demandas em busca do apoio psicológico por idosos no Serviço Escola de Psicologia (SEPSI) da Universidade de Gurupi

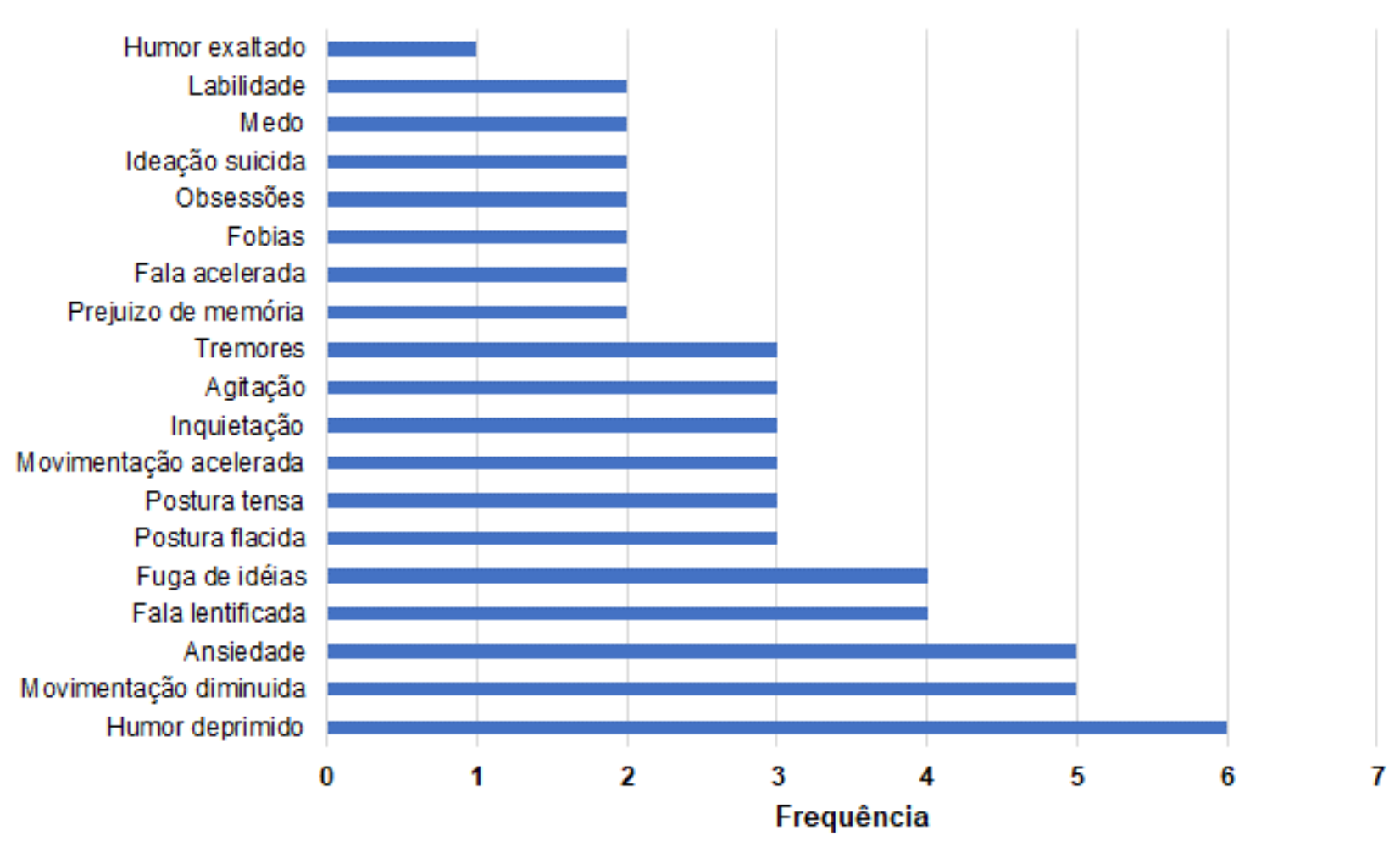

Figura 8. Observações da equipe de psicologia durante a triagem de idosos atendidos no Serviço Escola de Psicologia (SEPSI) da Universidade UnirG em Gurupi-TO entre os anos de 2015 a 2018.

Diante dos atendimentos realizados com idosos, nota-se que observações do comportamento foram analisadas durante a triagem e entre elas destacam-se com mais frequência humor deprimido, ansiedade, movimentação diminuída. Estes comportamentos podem estar relacionados diretamente com as queixas trazidas pelos idosos.

Após a realização dos atendimentos clínicos, realizam-se os devidos encaminhamentos, através da discussão, análise e supervisão entre acadêmicos estagiários e docentes supervisores, os quais são descritos na Figura 9: 


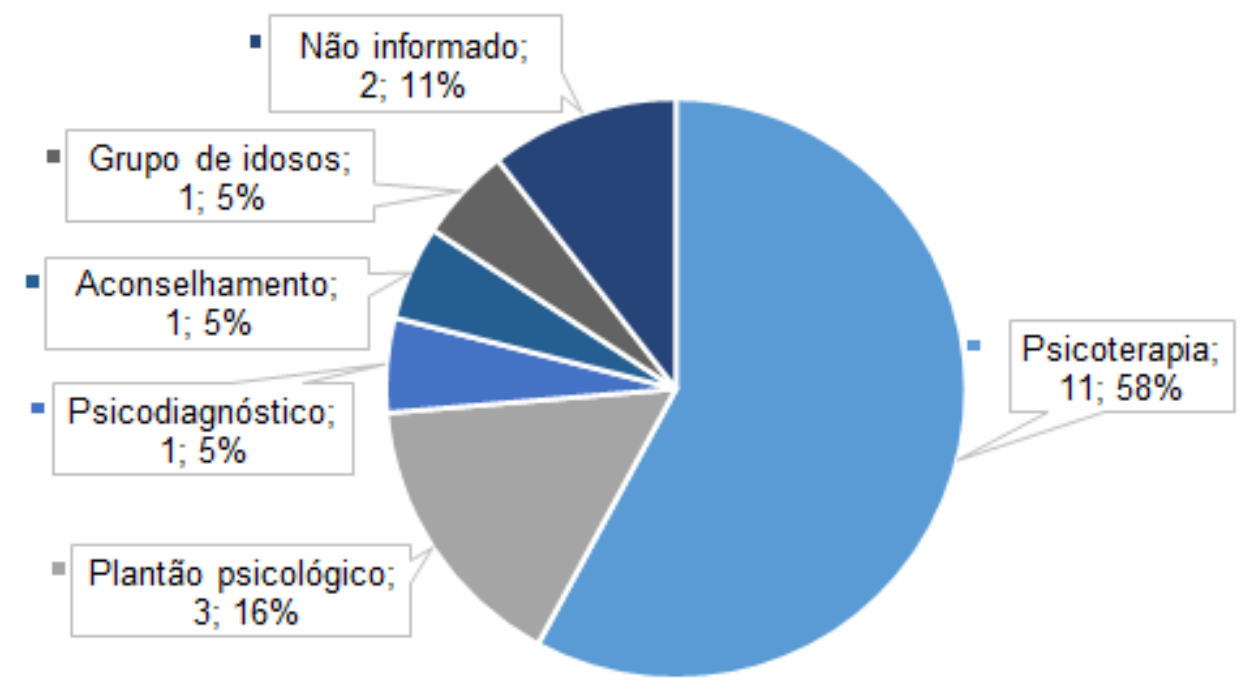

Figura 9. Encaminhamentos após triagem de idosos atendidos no Serviço Escola de Psicologia (SEPSI) da Universidade UnirG em Gurupi-TO entre os anos de 2015 a 2018.

É importante enfatizar que 58\% (11 idosos) foram encaminhados para a psicoterapia, já 16\% (3 idosos) para o plantão psicológico, 11\% (2 idosos) dos encaminhamentos não foram informados o destino e os demais tiveram encaminhamentos para atendimento de aconselhamento psicológico, Grupo de Idosos e Psicodiagnóstico, todos com 5\% (1 idoso) cada (Figura 9). A urgência destes encaminhamentos também foram variadas, e são apresentadas na Figura 10.

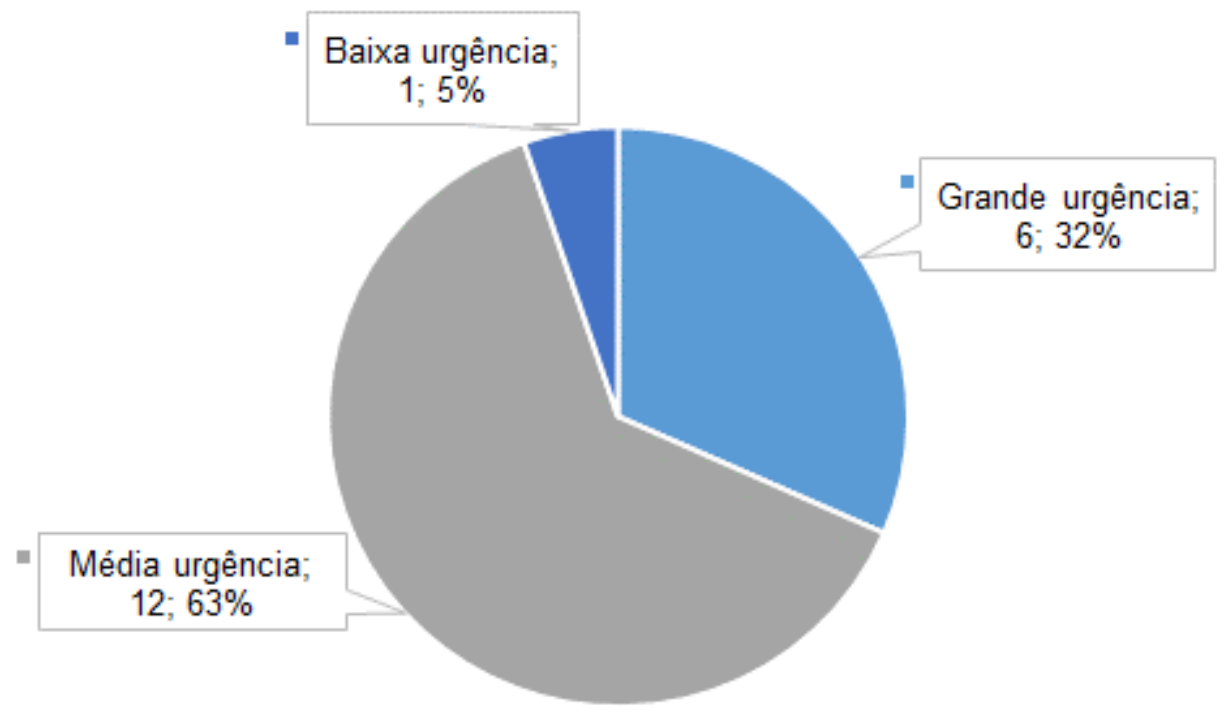

Figura 10. Grau de urgência de encaminhamentos de idosos atendidos no Serviço Escola de Psicologia (SEPSI) da Universidade UnirG em Gurupi-TO entre os anos de 2015 a 2018. 
Em relação à urgência dos encaminhamentos, 63\% (12 idosos) foram encaminhados com média urgência, e 32\% (6 idosos) foram encaminhados com grande urgência, e apenas $5 \%$ (1 idoso) não necessitaram de atendimento com urgência.

Ressalta-se que os encaminhamentos e avaliação de urgência são sugeridos em supervisão da disciplina de estágio, entre estagiários acadêmicos (que realizam os atendimentos) e supervisores (profissionais psicólogos e docentes da instituição).

Considera-se de urgência, os atendimentos em que são detectadas vulnerabilidades, que fornecem riscos à vida do paciente, bem como de terceiros que estejam ligados aos mesmos.

\section{CONSIDERAÇOES FINAIS}

Esta pesquisa demonstrou que a maioria dos idosos que buscaram apoio psicológico no SEPSI entre os anos de 2015 e 2018 são casados e do sexo feminino. Em relação às queixas, observou-se um predomínio de tristeza, choro frequente e solidão, e a partir delas é notório que a prevalência destas queixas que acompanham grande parte dos idosos, é devido a fatores relacionados ao envelhecimento, tais como: perdas, preocupações, complicações de saúde, entre outros. Desta forma, identificou-se que estes fatores podem gerar um adoecimento psíquico do idoso, que os levam a buscar ajuda, como foi percebido no Serviço Escola de Psicologia, sendo que a maioria destes foram encaminhados para psicoterapia.

A presente pesquisa foi fundamental para identificar as principais demandas trazidas por idosos, além de proporcionar um esclarecimento acerca da realidade vivenciada pelos mesmos, explicitando que a atenção voltada para eles não necessita unicamente do olhar médico, mas também se faz necessária a atenção psicológica, para promover uma melhor qualidade de vida significativa desta população.

Acredita-se que haja necessidade de desenvolver estudos que investiguem a saúde mental dos idosos e sua qualidade de vida, em especial aqueles habitam o município de Gurupi- TO, bem como, entendimento acerca das demandas destes, para subsidiar a edificação de técnicas e intervenções, atreladas a qualificações de profissionais, a fim de proporcionar um atendimento eficaz. Portanto, esta pesquisa é de grande relevância, pois possibilitou melhores informações a respeito da saúde mental na terceira idade, já que de acordo com estudos é visto que a população idosa cresce gradativamente. No entanto, 
DOI: 10.18606/2318-1419/amazonia.sci.health.v7n3p93-110 Revista Amazônia: Science \& Health

2019, Vol. 7, № 3 .

ISSN: 2318-1419
Sousa MP. Carvalho NJP. Aquino LQA.

O perfil do idoso e análise das principais demandas em busca do apoio psicológico por idosos no Serviço Escola de Psicologia (SEPSI) da Universidade de Gurupi.

ainda há carência de estudos que enfatizam os aspectos biopsicossociais e seus fatores de vulnerabilidade, e com os resultados dessa pesquisa pretendeu-se divulgar dados que potencializem a atuação dos profissionais da saúde, sobretudo os psicólogos.

\section{REFERÉNCIAS}

1. Instituto Brasileiro de Geografia e Estatística - IBGE.. PNAD- Pesquisa por Amostra de Domicílios: Características gerais dos domicílios e dos moradores. Rio de Janeiro-RJ: IBGE, Coordenação de Trabalho e Rendimento; 2019. 8 p. Disponível em: https://biblioteca.ibge.gov.br/index.php/bibliotecacatalogo? view=detalhes\&id=2101654. Acesso em: 02 maio 2019.

2. Barreto, J. Envelhecimento e qualidade de vida: o desafio actual. Sociologia, 15: 289-302. 2005. Disponível em: <http://www.redalyc.org/articulo.oa?id=426540419012>. Acesso em: 09 abr. 2019.

3. Vagetti GC, Moreira NB, Barbosa Filho VC, Oliveira V, Cancian CF, Mazzardo O et al. Domínios da qualidade de vida associados à percepção de saúde: um estudo com idosas de um programa de atividade física em bairros de baixa renda de Curitiba, Paraná, Brasil. Ciênc. saúde coletiva. 2013; 18(12):34833493. doi: 10.1590/S1413-81232013001200005.

4. Santos MM, Gerlach K; Drügg AMS. Psicologia do envelhecimento. Salão do Conhecimento; 2015. ljuíRS: UNIJUÍ - Universidade Regional do Noroeste do Estado do Rio Grande do Sul. Disponível em:<https://www.publicacoeseventos.unijui.edu.br /index.php/salaoconhecimento/article/view/486 8>. Acesso em: 10 abr. 2018.

5. González A, Ignácio ZM, Jornada L, Réus G, Abelaira H, Bernardini M et al. Transtornos depressivos e algumas comorbidades em idosos: um estudo de base populacional. Rev Bras Geriatr Gerontol. 2016; 19(1):95-103. doi: 10.1590/1809-9823.2016.14210

6. Santos KAS, Cendoroglo MS, Santos FC. Anxiety disorder in elderly persons with chronic pain: frequency and associations. Rev Bras Geriatr Gerontol. 2017; 20(1): 91-98. doi: 10.1590/1981-22562017020.160033

7. Rabelo DF, Neri AL. Tipos de configuração familiar e condições de saúde física e psicológica em idosos. Cad Saúde Pública. 2015; 31(4): 874-884. doi: 10.1590/0102-311X00087514.

8. Figueiredo Neto EM. Nível de atividade Física, Capacidade Funcional e Qualidade de Vida de Idosos Cadastrados nos Centros de Atenção a Melhor Idade-(CAIMI) da Cidade de Manaus. 2018. 101f. Tese [Doutorado em Saúde Coletiva]-Universidade Estadual Paulista, "Júlio de Mesquita Filho", Faculdade de Medicina de Botucatu, São Paulo.

9. Silva MP, Lôbo M, Marinho RS. Psicoterapia breve psicodinâmica com idoso: uma possibilidade para a qualidade de vida. Psicologia.Pt - O Portal dos Psicólogos [Internet]. 2014. Disponível em:< http://www.psicologia.pt/artigos/textos/A0747.pdf>. Acesso em 30 de mar 2019.

10.Silva JC, Herzog LM. Psicofármacos e psicoterapia com idosos. Psicol Soc. 2015; 27(2):438-448. doi: 10.1590/1807-03102015v27n2p438

11.BRASIL. Lei n. 8.213, 24 de julho de 1991. Dispõe sobre os Planos de Benefícios da Previdência Social e dá outras providências. Brasília: Diário Oficial da União; 24 jul 1991,. Disponível em <http://www.planalto.gov.br/ccivil_03/LEIS/L8213cons.htm>. Acesso em: 11 jul 2019.

12.Soares AVML. A relação juventude e educação em diferentes gerações: a perspectiva de estudantes da educação de jovens e adultos em uma Escola Municipal de Feira de Santana-BA. Feira de Santana-BA. Dissertação [Mestrado em Educação]-Universidade Estadual de Feira de Santana, Programa de PósGraduação em Educação, 2013. 
DOI: 10.18606/2318-1419/amazonia.sci.health.v7n3p93-110 Revista Amazônia: Science \& Health

2019, Vol. 7, № 3 .

ISSN: 2318-1419
Sousa MP. Carvalho NJP. Aquino LQA.

O perfil do idoso e análise das principais demandas em busca do apoio psicológico por idosos no Serviço Escola de Psicologia (SEPSI) da Universidade de Gurupi.

13.Siqueira GR, Vasconcelos DT, Duarte GC, Arruda IC, Costa JAS, Cardoso RO. Análise da sintomatologia depressiva nos moradores do Abrigo Cristo Redentor através da aplicação da Escala de Depressão Geriátrica (EDG). Ciênc Saúde Coletiva. 2009; 14(1):253-9. doi: /10.1590/S1413-81232009000100031.

14.Freitas PCB. Solidão em Idosos-Percepção em Função da Rede Social. Braga-PT. Dissertação [Mestrado em Gerontologia Social Aplicada] - Faculdade de Ciências Sociais, Universidade Católica Portuguesa, Centro Regional de Braga, Portugal, 2011. 